\title{
A Study of a Mutant Elongation Factor Properties of E. coli HAK88 and Its Mutant Elongation Factor Tu
}

\author{
Peggy G. Lemaux \\ University of Michigan, Medical School, Department of Microbiology, Ann Arbor, Michigan 48109, USA \\ David Lee Miller \\ Roche Institute of Molecular Biology, Nutley, New Jersey 07110, USA
}

\begin{abstract}
Summary. The E. coli chromosome contains two genes for elongation factor $\mathrm{Tu}, t u f A$ (near the fusidic acid resistance marker) and $t u f B$ (near the rifampicin resistance marker). It has been discovered that the mutant E. coli K12 strain HAK88 bears a mutation in the tufB gene, which leads to the synthesis of a protein of increased acidity. To determine whether the mutation has altered the protein's function in peptide chain elongation, we have compared the reactivities of normal tuf $A$ EF-Tu and mutant tufB EF$\mathrm{Tu}$ (purified together from HAK88) with the components of the AA-tRNA binding cycle. Normal tufA EF-Tu and mutant tufB EF-Tu are indistinguishable in their affinities for GDP, EF-Ts, and phe-tRNA, and differ only slightly in their affinities for ribosomes. Coupled with the results of a separate study showing the similarity of the normal tuf $A$ and tufB gene products, these experiments demonstrate that the mutation has not altered the function of tufB EF$\mathrm{Tu}$ in peptide chain elongation. Contrary to the original report (Kuwano et al., 1974; J. Mol. Biol. 86, 689-698) the HAK 88 strains we have examined no longer possess a temperature-sensitive EF-Ts. The growth rates of HAK88 strains resemble the parent HAK 8 strain in their lack of tRNA dependence but unlike HAK 8 show varying degrees of temperature sensitivity. We conclude that HAK88 contains a physically altered but functionally intact tufB EF-Tu. The mutation in $t u f B$ should be valuable for studying in vivo the control of expression of the genes for EF$\mathrm{Tu}$.
\end{abstract}

\section{Introduction}

Elongation factor $\mathrm{Tu}(\mathrm{EF}-\mathrm{Tu})$ promotes the binding of aminoacyl-tRNA (AA-tRNA) to ribosomes in response to the appropriate codon in messenger RNA (Lucas-Lenard and Lipmann, 1971; Lucas-Lenard and Beres, 1974; Miller and Weissbach, 1977). The

For offprints contact: D.L. Miller cycle of reactions by which EF-Tu binds AA-tRNA to ribosomes consists of four steps, which are summarized in the following equations:

$$
\begin{aligned}
& \mathrm{EF}-\mathrm{Tu} \cdot \mathrm{GDP}+\mathrm{EF}-\mathrm{Ts} \rightleftharpoons \mathrm{EF}-\mathrm{Tu} \cdot \mathrm{EF}-\mathrm{Ts}+\mathrm{GDP} \\
& \mathrm{EF-Tu} \cdot \mathrm{EF}-\mathrm{Ts}+\mathrm{GTP} \rightleftharpoons \mathrm{EF}-\mathrm{Tu} \cdot \mathrm{GTP}+\mathrm{EF}-\mathrm{Ts} \\
& \mathrm{EF-Tu} \cdot \mathrm{GTP}+\mathrm{AA}-\mathrm{tRNA} \\
& \quad \rightarrow \mathrm{AA}-\mathrm{tRNA} \cdot \mathrm{EF}-\mathrm{Tu} \cdot \mathrm{GTP} \\
& \mathrm{AA-tRNA} \cdot \mathrm{EF}-\mathrm{Tu} \cdot \mathrm{GTP}+\text { ribosomes } \cdot \mathrm{mRNA} \\
& \quad \rightarrow \mathrm{AA}-\mathrm{tRNA} \cdot \text { ribosomes } \cdot \mathrm{mRNA}+\mathrm{GDP}+\mathrm{Pi} .
\end{aligned}
$$

As one of the host-donated components of bacteriophage $\mathrm{Q} \beta$ replicase, the protein also participates in phage-specific RNA synthesis (Blumenthal et al., 1972). In addition, it has been reported that EF-Tu together with EF-Ts stimulates E. coli RNA polymerase under certain conditions (Travers, 1973). To understand how EF-Tu regulates these processes, it would be useful to examine the behavior of bacterial strains bearing a mutant EF-Tu and to characterize the functional defects in the altered protein.

Until recently, no such strain had been reported. One of the difficulties in isolating EF-Tu mutants is explained by the discovery that the E. coli chromosome contains at least two genes for EF-Tu (Jaskunas et al., 1975), the products of which are at present indistinguishable in their physical and functional properties. Recently, however, using the technique of two-dimensional isoelectric focusing-SDS gel electrophoresis, Pedersen et al. (Pedersen et al., 1976a) discovered that the $E$. coli K12 mutant strain HAK 88 possesses an altered form of EF-Tu which differs in isoelectric point from normal EF-Tu and which has been shown to be the product of a mutation in the tufB gene. ${ }^{1}$

Since the HAK 88 strain had originally been selected for its growth dependence upon exogeneous tRNA at elevated temperatures (Kuwano et al.,

1 tuf $A$ is the EF-Tu gene adjacent to the fus marker on the $E$. coli chromosome, and tufB is the EF-Tu gene near the rif marker (Jaskunas et al., 1975) 
1972), we thought there might be a difference in the reactivities of the normal and mutant EF-Tu's with AA-tRNA or some other component of the protein synthetic apparatus. The following report compares the normal tufA EF-Tu and mutant tufB EF-Tu in their reactions with EF-Ts, GDP, AA-tRNA and ribosomes. In addition, we examined some of the properties of the HAK 88 strain itself and of HAK 88 EF-Ts, since the original strain was reported to have a temperature-sensitive EF-Ts (Kuwano et al., 1974).

The comparison of mutant $t u f B$ EF-Tu to normal tuf $A$ EF-Tu does not tell us directly whether the mutation has altered the function of the $t u f B$ gene product; however, additional experiments (D.L. Miller et al., accompanying paper) have shown that there are only minor differences in the reactivities of the normal tuf $A$ and tufB gene products in the AAtRNA binding cycle. As a consequence, by comparing the functions of the normal and mutant species from HAK88, we can determine the effect of the mutation upon the functions of tufB EF-Tu.

\section{Experimental Procedures}

\section{Materials}

Ultrogel AcA44 is a product of LKB. Guanylyl imidodiphosphate (GMPNP) and GDP were obtained from P.L. Laboratories, Inc. Sepharose 6B was purchased from Pharmacia, Inc. EF-Tu was prepared from normal E. coli B as well as from strain HAK 88 by a previously described procedure (Miller and Weissbach, 1974). The purification procedure does not separate normal EF-Tu from altered EF-Tu although they can be resolved by preparative isoelectric focusing (P. Lemaux, unpublished data). EF-Ts was also purified by a published method (Hachmann et al., 1972). $\left[{ }^{35} \mathrm{~S}_{\mathrm{K}_{2}} \mathrm{SO}_{4}\right.$ was purchased from New England Nuclear. Deacylated $E$. coli B tRNA was purchased from Calbiochem. Salt-washed $70 \mathrm{~S}$ ribosomes were kindly supplied by Drs. Nathan Brot and Fred Chu.

\section{Methods}

Bacterial Strains. An E. coli K12 (W3110) derivative, HAK88, was used for these studies. This strain is reported to have the following characteristics: trp ${ }^{-}$, rel $^{+}$, RNase I-, EF-Ts ${ }^{\text {ts }}$ and RNA ${ }^{\text {perm }}$ (Glazier and Schlessinger, 1974). The source of the strain used for the purification and characterization was A.A. Travers via $K$. von Meyenberg (HAK88-AT). Additional growth characterization was carried out on strains obtained recently from $M$. Kuwano (HAK88-MK) and D. Schlessinger (HAK88-DS). The HAK8 strain used was also obtained from A.A. Travers via $K$. von Meyenberg.

\section{Bacterial Growth and Labeling}

The growth of the HAK88 culture for EF-Tu purification was carried out in a MOPS-buffered medium (Neidhardt et al., 1974) containing: $0.4 \%$ glucose, $1.32 \mathrm{mM} \mathrm{K} \mathrm{K}_{2} \mathrm{HPO}_{4}, 0.2 \%$ casamino acids, $0.1 \mathrm{mM}$ L-tryptophan and $7 \mu \mathrm{g} / \mathrm{ml}$ thiamine. Cells were grown at $30^{\circ}$ and had an approximate doubling time of $120 \mathrm{~min}$.

Cells labeled with $\left[{ }^{35} \mathrm{~S} \mathrm{~K}_{2} \mathrm{SO}_{4}\right.$ were grown as described above except that no casamino acids were added to the medium and unlabelled $\mathrm{SO}_{4}$ was added to a level of $0.028 \mathrm{mM}$. Labeling was performed using $\left[{ }^{35} \mathrm{~S}\right] \mathrm{K}_{2} \mathrm{SO}_{4}$ at a final level of $50 \mu \mathrm{Ci} / \mathrm{ml}$.

Some growth experiments were carried out using MOPS minimal agar plates of the composition described above for EF-Tu purification except that no casamino acids were added. Deacylated E. coli B tRNA was dissolved in MOPS minimal medium in $50 \%$ excess (to account for losses during filtration), filtered through a 0.45 micron cellulose nitrate filter and then added to molten agar (equilibrated to approximately $55^{\circ}$ ). Inocula used for these experiments were calibrated so that approximately equal numbers of organisms were added to each plate. Relative growth was a subjective assessment of the growth at a given temperature relative to the amount of growth of the given culture at $28^{\circ} \mathrm{C}$. The amount of growth at $28^{\circ} \mathrm{C}$ was defined as $4+$.

A totally defined rich medium with the MOPS-buffering system was used for growth experiments in liquid medium. Glucose $(0.4 \%)$ was used as the carbon source and $20 \mathrm{~L}$-amino acids, four nucleic acid bases and five vitamins were added to this as described (Neidhardt et al., 1977). Cultures were grown aerobically in Erlenmeyer flasks with rotary shaking. Growth rates were determined at culture densities between $\mathrm{A}_{420} 0.1$ and 3.0 by suitably diluting the cultures prior to absorbance measurements. Eight minutes prior to the shift, portions of the culture were transferred to new flasks, one containing tRNA (to a final concentration $2 \mathrm{mg} / \mathrm{ml}$ ) and one not. Temperature shifts were completed in less than $15 \mathrm{~s}$.

\section{EF-Tu Purification}

Approximately $30-35 \mathrm{~g}$ of cells were suspended in $30-40 \mathrm{mls}$ of cold buffer containing: $120 \mathrm{mM} \mathrm{NH}{ }_{4} \mathrm{Cl} ; 10 \mathrm{mM} \mathrm{mgCl} ; 10 \mathrm{mM}$ Tris $\cdot \mathrm{HCl} ; \mathrm{pH} 8.0 ; 10 \mathrm{mM} \beta$-mercaptoethanol. The cells were then disrupted in a French Pressure Cell at 1000 psi. After removing the debris by centrifugation, the EF-Tu from the cell supernatant was purified as described previously (Miller and Weissbach, 1974). To prepare $\left[{ }^{35} \mathrm{~S}\right]$-labeled EF-Tu, approximately $20 \mathrm{mg}$ of cells labeled with $\left[{ }^{35} \mathrm{~S}\right] \mathrm{K}_{2} \mathrm{SO}_{4}$ were harvested by centrifugation and resuspended in the cold buffer described above (plus $10 \%$ glycerol). The cells were ruptured by sonication and then centrifuged to remove debris. The cell supernatant was passed through a $1 \times 60 \mathrm{~cm}$ Ultrogel AcA44 column equilibrated with the buffer previously described and the fractions containing EF-Tu, to which $2 \mathrm{mg}$ of bovine albumin were added, were concentrated using an Amicon B-15 mini-concentrator.

\section{Assay Procedures}

Isoelectric Focussing Procedures. The relative amounts of the two EF-Tu species were determined by photometric scanning of the protein bands separated by isoelectric focusing. Mixtures of normal and mutant EF-Tu were resolved on $2.0 \times 10 \mathrm{~cm}$ gels of $4 \%$ polyacrylamide made to give an effective isoelectric focusing range of $\mathrm{pH} 4.6$ to 7.8, as described elsewhere (O'Farreil, 1975). The gels were extruded directly into a fixing solution $(30 \%$ methanol, $3.45 \%$ sulfosalicyclic acid, $11,5 \%$ trichloroacetic acid) for $30 \mathrm{mi}-$ nutes and then transferred to a staining solution $(0.12 \%$ Coomassie Brilliant Blue, $25 \%$ ethanol, $8 \%$ glacial acetic acid) for 10 minutes at $55^{\circ} \mathrm{C}$. The gels were destained in a $25 \%$ ethanol $-8 \%$ glacial acetic acid solution for $3 \mathrm{~h}$ at $28^{\circ} \mathrm{C}$ and then refrigerated. The gels were scanned at $570 \mathrm{~nm}$ using a Gilford spectrophotometer equipped with a linear transport. The scanning speed was $0.5 \mathrm{~cm} / \mathrm{min}$ 
and the $0.05 \mathrm{~mm}$ slit was masked so that all of the light passed through the gels. Two-dimensional gels were run essentially by the method of O'Farrell (O'Farrell, 1975) with modifications previously described (Pedersen et al., 1976b).

Gel Filtration Procedures. The interaction between E. coli B EF-Ts and the mixture of normal and mutant EF-Tu from the HAK 88 strain was examined by gel filtration. Ef-Tu (1 nmole) and EF-Ts ( 4 nmoles) were chromatographed on a $1.6 \times 60 \mathrm{~cm}$ column of U1trogel AcA44 equilibrated with $10 \mathrm{mM}$ Tris- $\mathrm{HCl}, \mathrm{pH} 8.0,10 \mathrm{mM}$ $\mathrm{MgCl}_{2}, 10 \mathrm{mM}$ mercaptoethanol. The fractions containing the EF$\mathrm{Tu} \cdot \mathrm{EF}-\mathrm{Ts}$ complex were identified by cellulose nitrate filter assays for the binding of $\left[{ }^{3} \mathrm{H}\right]$ GDP to EF-Tu (Miller and Weissbach, 1974). The relative amounts of the two EF-Tu species were determined by the isoelectric focusing procedure described in the previous paragraph.

The relative affinities of EF-Ts and GDP for the two EF-Ts species were determined by chromatographing the same mixture of EF-Tu and EF-Ts described in the preceding paragraph under the same conditions, except that the buffer used to equilibrate the column contained either $5 \mu \mathrm{M}$ or $20 \mu \mathrm{M}$ GDP. GDP tends to displace EF-Ts from EF-Tu and the proteins emerge later from the column, at the elution volumes of the separate components. Therefore, the elution profile of EF-Tu is controlled by the extent to which GDP competes with EF-Ts.

To measure the binding of AA-tRNA to the normal and mutant EF-Tu, the conventional cellulose nitrate filter assay was used (Miller and Weissbach, 1974). In this assay, EF-Tu.GTP binds to the filter while AA-tRNA.EF-Tu.GTP passes through and is recovered in the filtrate. EF-Tu $(140 \mathrm{pmol})$ was treated with $20 \mu \mathrm{g}$ pyruvate kinase for $5 \mathrm{~min}$ at $37^{\circ} \mathrm{C}$ in $0.2 \mathrm{ml}$ of a buffer composed of $50 \mathrm{mM}$ Tris $\cdot \mathrm{HCl}$, pH $7.2 ; 10 \mathrm{mM} \mathrm{MgCl} ; 1 \mathrm{mM}$ DTT; $100 \mathrm{mM} \mathrm{NH}_{4} \mathrm{Cl} ; 1 \mathrm{mM}$ phosphoenolpyruvate; $20 \mu \mathrm{M}$ $\left[{ }^{3} \mathrm{H}\right] \mathrm{GTP}$. This was done in order to convert all of the EF-Tu to the EF-Tu - GTP complex. Then $180 \mathrm{pmol}$ of phe-tRNA was added and after $3 \mathrm{~min}$ at $37^{\circ} \mathrm{C}$ the mixture was filtered through a cellulose nitrate filter. The amount of ternary complex formed was calculated from the difference in the amounts of filter-bound GTP in the absence and presence of phe-tRNA. The filtrate was concentrated by lyophilization and was analyzed by two-dimensional isoelectric focusing-SDS gel electrophoresis.

The ternary complex phe-tRNA-EF-Tu-GMP-PNP will bind to ribosomes programmed with poly(U). The relative efficiencies with which the normal and mutant EF-Tu bind to ribosomes were determined by treating $E$. coli $\mathrm{B}$ ribosomes bound to poly $(\mathrm{U})$ with the partially purified EF-Tu from $\left[{ }^{35} \mathrm{~S}\right]$-labeled cells. The ternary complex was formed by incubating the $\left[{ }^{35} \mathrm{~S}\right] \mathrm{EF}-\mathrm{Tu}$ $(100 \mathrm{pmol}, 25,000 \mathrm{cpm})$ with pyruvate kinase as described above, except that $50 \mu \mathrm{M}$ GMP.PNP was substituted for GTP. Then $120 \mathrm{pmol}$ of phe-tRNA was added and the mixture was reincubated for $3 \mathrm{~min}$ at $37^{\circ} \mathrm{C}$. After cooling in ice and following the addition of $4 \mathrm{~A}_{260}$ ribosomes and $5 \mu \mathrm{gm}$ poly(U), the mixture was passed through a $0.5 \times 20 \mathrm{~cm}$ column of Sepharose $6 \mathrm{~B}$ (equilibrated with $50 \mathrm{mM}$ Tris $\mathrm{HCl}, \mathrm{pH} 7.4,150 \mathrm{mM} \mathrm{NH} 4 \mathrm{Cl}, 12 \mathrm{mM} \mathrm{MgCl}_{2}$ ). The early fractions containing radioactive protein bound to ribosomes were concentrated by lyophilization and analyzed by twodimensional electrophoresis.

\section{Poly(U)-Dependent Polypeptide Synthesis Assays}

These assays were carried out as described (Gordon et al., 1971). Charged tRNA was made using deacylated $E$. coli $\mathrm{B}$ tRNA and $\left[{ }^{14} \mathrm{C}\right]$-phenylalanine $(50 \mu \mathrm{Ci} / \mathrm{ml}$ in $0.01 \mathrm{~N} \mathrm{HCl})$ according to the procedure of Gordon (Gordon, 1970). Ribosomes were prepared from $E$. coli CSH59 which was starved for uracil and treated with rifampicin to deplete endogenous mRNA. The ribosomes were salt-washed 7 times to deplete them of any residual EF-Tu or EF$\mathrm{G}$ activity. (By omitting the appropriate purified factors, it was shown that these ribosomes lacked any significant EF-Ts, EF-Tu, or EF-G activity.) Purified EF-G and EF-Tu were kindly supplied by F. Young; EF-Ts was kindly supplied by S. Pedersen.

\section{Results}

Purification of the Normal and Mutant Proteins. The two EF-Tu gene products ( $t u f A$ and $t u f B$ ) from wildtype E. coli cannot be separated by the normal scheme used to purify EF-Tu to apparent homogeneity, a scheme which includes DEAE Sephadex chromatography, gel filtration and ammonium sulfate extraction. The normal gene products are not resolved by conventional isoelectric focusing either. Although isoelectric focusing in a sucrose gradient produces multiple bands of EF-Tu from wild-type $E$. coli $\mathrm{B}$, the bands are apparently caused by some type of inhomogeneity such as partial deamidation or end group modification. Photometric scanning of an isoelectric focusing gel of EF-Tu from wild-type $E$. coli $\mathrm{B}$, containing normal tuf $A$ and tufB gene products, shows a broad band with a few minor, primarily more acidic, side bands (Fig. 1A). These side bands are not related to differences between the two genes since each protein, isolated from cells infected with a phage bearing the tuf $A$ or tufB gene, shows a

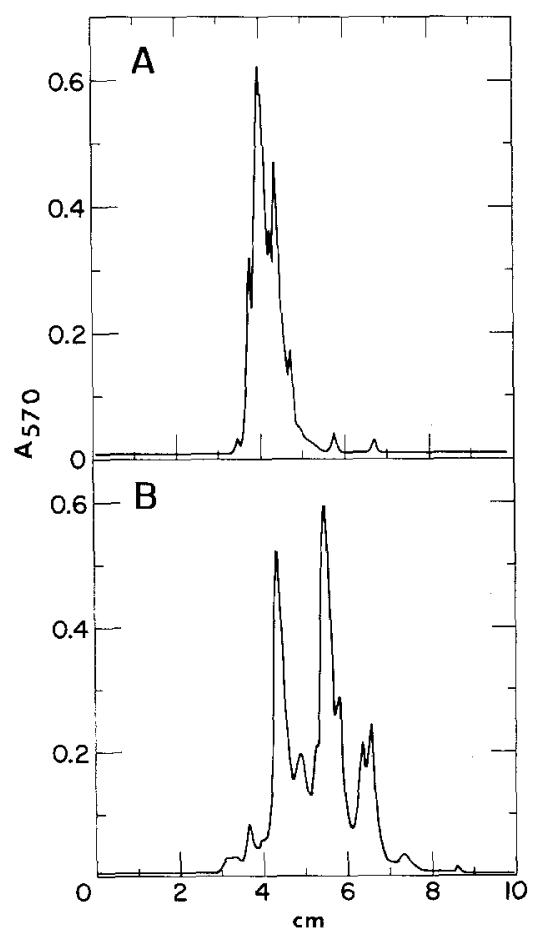

Fig. $1 \mathrm{~A}$ and B. Photometric scans of stained isoelectric focusing gels. A EF-Tu from $E$. coli B. B EF-Tu from $E$. coli K12, HAK 88 strain 


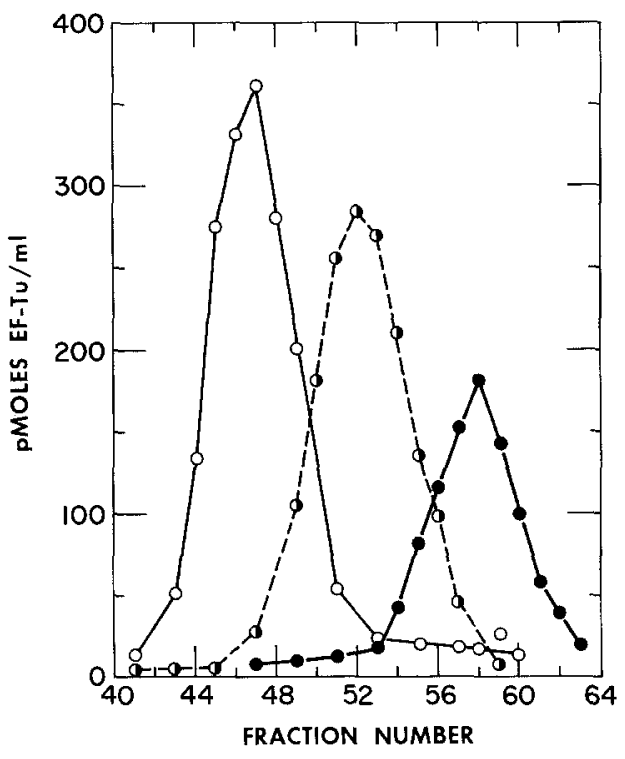

Fig. 2. Elution profiles of HAK 88 EF-Tu.GDP, EF-Tu-EF-Ts, and EF-Tu+EF-Ts + GDP. All three separations were performed on an AcA44 Ultrogel column as described in the text. EF-Tu activity was measured by $\left[{ }^{3} \mathrm{H}\right]$-GDP binding. $-25 \mu \mathrm{gm} \mathrm{EF}$ Tu.GDP; O- $O 50 \mu \mathrm{gm}$ EF-Tu+100 $\mu \mathrm{gm}$ EF-Ts; o$50 \mu \mathrm{gm}$ EF-Tu $+100 \mu \mathrm{gm}$ EF-Ts, column equilibrated with $20 \mu \mathrm{M}$ GDP

similarly disperse band. We believe this broadening is caused by a modification of the protein, for example, by deamidation of glutamine or asparagine, most probably during purification. Whole cell extracts of wild-type E. coli B do not show multiple satellite spots for EF-Tu (Neidhardt et al., 1977) nor do extracts from HAK88 (Pedersen et al., 1976a).

The two EF-Tu gene products from the HAK 88 mutant are also co-purified by the normal procedure; however, upon isoelectric focusing, the mutant EF-Tu is resolved as a more acidic band (Fig. 2B), which corroborates the preliminary purification data obtained by Pedersen et al. (Pedersen et al., 1976a).

The ratio of mutant EF-Tu to normal EF-Tu in lysates of cells grown in glucose minimal medium, as determined by two-dimensional gel electrophoresis of ${ }^{35} \mathrm{~S}$-labeled cell lysates, is usually about 0.4 (Pedersen et al., 1976a). The ratio of the amounts of the two proteins after purification, determined by photometric scanning of stained IEF gels, is about 1.2 (tufB/tufA) (Table 1). This difference in the ratios indicates either a preferential purification of $t u f B$ gene product during the preparation or an enhanced affinity of that protein for the stain. For whichever reason, the ratios seem fairly reproducible. An independent purification of the two EF-Tu's from HAK 88 gave a similar ratio. Amounts of $1.0 \mu \mathrm{g}$, $0.5 \mu \mathrm{g}$ and $0.1 \mu \mathrm{g}$ of protein (approximately 95\% pure) were focused, stained and scanned and the ratio
Table 1. Ratios of mutant to wild-type HAK 88 EF-Tu in fractions from the three gel filtration experiments described in Figure 2

\begin{tabular}{ll}
\hline Fraction & $\begin{array}{l}\text { Ratio, mutant } \\
\text { EF-Tu/wild-type EF-Tu }\end{array}$ \\
\hline 1. EF-Tu-GDP & 1.2 \\
2. EF-Tu-EF-Ts & 1.1 \\
3. EF-Tu + EF-Ts + GDP, fract. 55 & 1.5 \\
EF-Tu +EF-Ts + GDP, fract. 57 & 2.2 \\
\hline
\end{tabular}

of $\operatorname{tufB} / \mathrm{tuf} A$ peaks was determined to be $1.2 \pm 0.3$ (standard deviation). The photometric scan of the EF-Tu from HAK 88 shows the mutant EF-Tu focusing at a more acidic $\mathrm{pH}$ than the wild-type EF-Tu (Fig. 1B). If a difference of one charge separates the adjacent bands seen in the scan of this preparation then the mutant EF-Tu appears to differ from the wild-type protein by two charges. The preparation of EF-Tu used for these studies was estimated by twodimensional electrophoresis to be approximately $96 \%$ pure.

Interaction with EF-TS. The strategy employed to compare the affinities of the normal tuf $A$ and mutant tufB proteins for EF-Ts involved combining a purified mixture of the EF-Tu proteins with a specified amount of EF-Ts, passing the mixture through a gel filtration column which separated EF-Tu-EF-Ts from its components (Miller and Weissbach, 1969), (Fig. 2) and then analyzing the complex by gel isoelectric focusing. The relative amounts of the two EF-Tu proteins were determined by photometric scanning of the stained gels. As the results in Table 1, Exp. 2 show, the ratio of the amounts of the two gene products bound to EF-Ts is similar to the ratio found initially in EF-Tu.GDP (Table 1, Exp.1) indicating that the wild-type and mutant EF-Tu bind to EF-Ts with similar affinities.

Interaction with GDP. The affinities of the two gene products for GDP were compared by allowing GDP to compete with EF-Ts for binding to the two EF-Tu species during gel filtration chromatography (Fig. 2). At concentrations of GDP below $1 \times 10^{-6} \mathrm{M}$ in the column buffer, the proteins emerged together as the EF-Tu.EF-Ts complex whereas at high concentrations of GDP (above $2 \times 10^{-5} \mathrm{M}$ ) the proteins emerged separately as EF-Tu.GDP and EF-Ts. At intermediate concentrations of GDP, the proteins emerged at an intermediate position as a rapidly equilibrating mixture of EF-Tu-EF-Ts, EF-Tu - GDP and EF-Ts. When $2 \times 10^{-5} \mathrm{M}$ GDP was used (Table 1, Exp. 3), in the intermediate fraction containing both complexes (fraction 55), the ratio of the mutant to wild-type EF-Tu was the same as in the original 


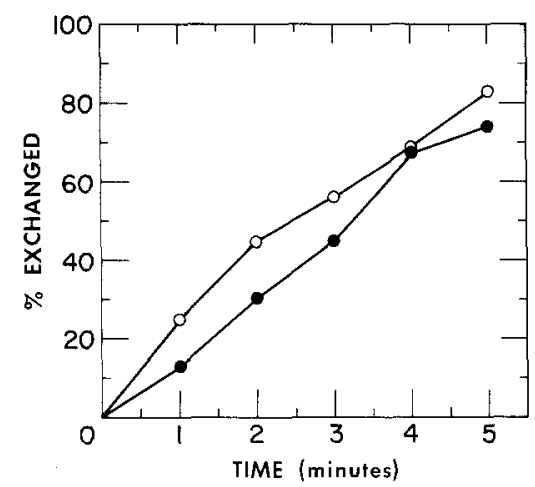

Fig. 3. Time course of exchange of GDP bound to E. coli B EF-Tu $(0-0)$ and HAK88 EF-Tu $(\bullet-)$ ) catalyzed by EF-Ts. Forty pmol EF-Tu. GDP from each organism was incubated at $0^{\circ}$ with $20 \mu \mathrm{M}\left[{ }^{3} \mathrm{H}\right]$ GDP and 1 pmol of EF-Ts in $200 \mu \mathrm{l}$ of a buffer composed of $50 \mathrm{mM}$ Tris $\mathrm{HCl}\left(\mathrm{pH} 7.5\right.$ ), $10 \mathrm{mM} \mathrm{MgCl}_{2}, 1 \mathrm{mM}$ DTT. The extent of exchange was measured by the cellulose nitrate filter assay

preparation within experimental error. In the EF$\mathrm{Tu}$. GDP fraction (fraction 57) the ratio is slightly higher, indicating that compared to wild-type EF-Tu, the mutant EF-Tu may bind GDP relatively more tightly than it binds EF-Ts. This result is less reliable than the other measurements quoted in Table 1 because the amount of EF-Tu in fraction 57 is low; consequently, we do not consider this apparent difference significant.

We learned something about relative rates of EFTs-catalyzed exchange of GDP with the two EF-Tu proteins by comparing the exchange profiles of normal E. coli EF-Tu with HAK88 EF-Tu. Figure 3 shows that the rates of exchange of the proteins from the two organisms are similar throughout the course of the reaction. From this we conclude that the mutant protein does not form an inhibitory complex with EF-Ts, and EF-Ts displaces GDP from the mutant EF-Tu efficiently.

Interaction with $A A-t R N A$. Since the mutant tufB protein comprises $60 \%$ of the total GDP binding activity in the HAK 88 mutant EF-Tu, we can measure directly the affinity of the mutant protein for AA-tRNA in the mixture. Table 2 compares the reactivity of EF-Tu from HAK88 with that of EF-Tu from $E$. coli B, using the cellulose nitrate filter assay. Since about $65 \%$ of the EF-Tu from each organism binds phe-tRNA, we conclude that the mutant EF$\mathrm{Tu}$ must react extensively with AA-tRNA. Even if all of normal EF-Tu ( $40 \%$ of the mixture) had reacted with phe-tRNA, nearly one-half of the mutant EF-Tu must also have reacted for the total reactivity to be $65 \%$. Actually, we expect that less than $100 \%$ of the normal EF-Tu reacted; and thus proportionately more of the mutant EF-Tu bound phe-tRNA. We
Table 2. Reactivity of EF-Tu from E. coli B of HAK 88 with phetRNA

\begin{tabular}{llll}
\hline Organism & \multicolumn{2}{l}{ Amount bound to filter, pmol. } & $\begin{array}{l}\% \text { EF-Tu in } \\
\text { ternary complex }\end{array}$ \\
\cline { 2 - 3 } & -phe-tRNA & + phe-tRNA & \\
\hline E. coli B & 141 & 51 & 64 \\
HAK88 & 145 & 51 & 65 \\
\hline
\end{tabular}

About $140 \mathrm{pmol}$ of EF-Tu from either organism was incubated with $\left[{ }^{3} \mathrm{H}\right]-\mathrm{GTP}, \mathrm{PEP}$ and pyruvate kinase to convert EF-Tu GDP to EF-Tu.GTP, as described in the text. EF-Tu.GTP was then incubated with 180 pmol of phe-tRNA, and the mixtures were filtered through Millipore HA filters. Identical mixtures without phe-tRNA were simultaneously filtered. The percent EF-Tu incorporated into the ternary complex was calculated as the fraction of EF-Tu released from the filter by the addition of phe-tRNA

confirmed this conclusion by isoelectric focusing analysis of the phe-tRNA.EF-Tu.GTP complex in the filtrate from this assay. As expected, both normal and mutant gene products were present in similar amounts in the ternary complex formed from HAK88 EF-Tu.

Under the conditions of the experiment, (the concentrations of EF-Tu and AA-tRNA were similar) the EF-Tu species were not competing for a limited amount of AA-tRNA; therefore, we do not know by how much the two species differ in their affinities for AA-tRNA. We do know that both species bind AAtRNA tightly with dissociation constants below $1 \mu \mathrm{M}$, the concentration of phe-tRNA used in the experiment.

Interaction with Ribosomes. The ternary complex phetRNA -EF-Tu.GMP.PNP containing both EF-Tu species, as described in the previous section, was added to ribosomes and poly(U) and then the mixture was passed through a Sepharose 6B column, which cleanly separates ribosome-bound AAtRNA.EF-Tu-GMP.PNP from the free complex. Analysis of the mixture (Table 3 ) shows that the wildtype protein binds to ribosomes with approximately twice the affinity of the mutant protein. Since these experiments were performed with a limiting quantity of active ribosomes, this value should represent the ratio of the affinity constants of the two proteins for the ribosomes.

Activity in Peptide Chain Elongation. Because EF-Tu is partially denaturated by isoelectric focusing (D.L. Miller, unpublished data), we were unable to measure any kinetic properties of the separated proteins. Nevertheless, the data in Table 4 show that the mixture of HAK 88 EF-Tu's is as active as a comparable amount of EF-Tu from HAK8 in the peptide chain elongation assay. Additionally, these data show that the mutant EF-Tu is non-inhibitory to the reaction. 
Table 3. Ratios of mutant (tufB) EF-Tu to wild-type (tufA) EF-Tu in the complex with phe-tRNA and ribosomes

\begin{tabular}{ll}
\hline Complex & $\begin{array}{l}\text { Ratio, mutant } \\
\text { EF-Tu/wild-type EF-Tu }\end{array}$ \\
\hline $\begin{array}{l}\text { 1. EF-Tu G GDP } \\
\text { 2. phe-tRNA } \text { EF-Tu GMP-PNP } \\
\text { ribosomes poly U }\end{array}$ & $0.84 \pm 0.00^{\mathrm{a}}$ \\
\hline
\end{tabular}

The complexes were formed from $\left[{ }^{35} \mathrm{~S}\right]$ methionine-labeled HAK 88 EF-Tu, and they were isolated as described in the text. Following 2-D isoelectric-focusing/SDS-electrophoresis, the radioactivity in each of the spots containing mutant and wild-type EF-Tu was determined. The ratio of EF-Tu. GDP species found in the partially purified protein mixture differs from that of the purified EF-Tu used in the preceding experiments

a These values represent the average of two separate determinations \pm the experimental deviation

Table 4. Activity of EF-Tu from HAK 88 in polyphenylalanine synthesis

\begin{tabular}{lr}
\hline Mixture & CPM polyphenylalanine \\
\hline Complete mixture & 2200 \\
- HAK88 EF-Tu & 114 \\
- HAK88 EF-Tu + HAK8 EF-Tu & 1715 \\
\hline
\end{tabular}

EF-Tu ( 2 pmol) from each bacterial strain was incubated with EFTs, EF ribosomes, poly $U$ and phe-tRNA, and polyphenylalanine formation was assayed as described

Thermal Stability of the Factors. Since the studies of the interactions of EF-Tu with EF-Ts and GDP were performed at $4^{\circ} \mathrm{C}$ and the studies of ternary complex formation and ribosome binding were conducted at $37^{\circ} \mathrm{C}$, it was possible that we could have missed detecting an alteration that decreased the stability of the tufB gene product at higher temperatures. Accordingly, we measured the rate of inactivation of GDPbinding at $51^{\circ} \mathrm{C}$ in the HAK $88 \mathrm{EF}-\mathrm{Tu}$ mixture and compared it to the rate of inactivation of normal EF$\mathrm{Tu}$ from $E$. coli B. If the mutant EF-Tu had an increased thermal sensitivity, the initial rate of denaturation of the EF-Tu mixture from HAK88 should have been higher than that of the normal mixture. The amounts of wild-type and mutant EF$\mathrm{Tu}$ in our purified mixtures were nearly equal (as determined by photometric scanning of stained gels), consequently, even a modest difference in the rates of denaturation should be apparent. As Figure 4A shows, the loss of GDP-binding activity in the mutant-containing EF-Tu mixture strongly resembles the denaturation characteristics of EF-Tu from $E$. coli $\mathrm{B}$. Both the wild-type and mutant-wild-type mixture of EF-Tu failed to obey simply first order kinetics of denaturation because the species that denaturated was free EF-Tu. As denaturation pro-

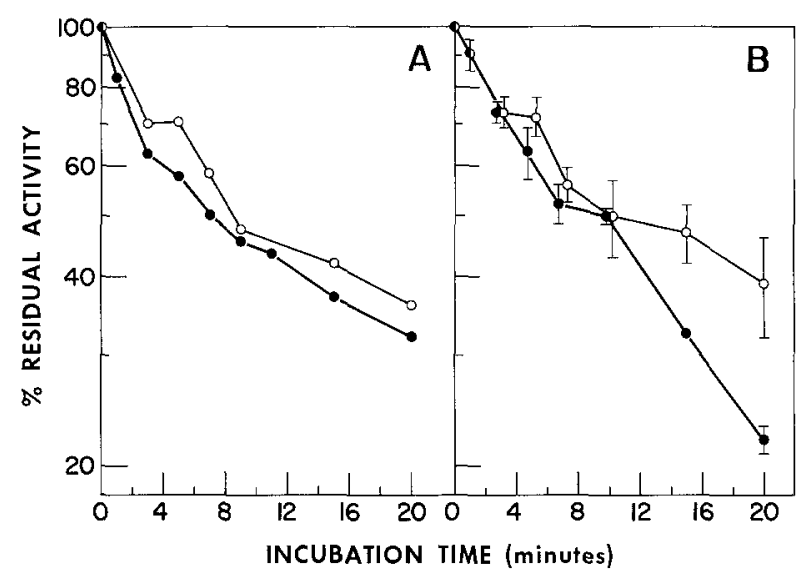

Fig. 4A and B. Thermal inactivation of EF-Tu from E. coli B and

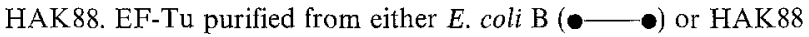
$\left(\mathrm{O} \longrightarrow\right.$ ) was incubated at $51^{\circ}$ at a concentration of $2200 \mathrm{pmol.ml}$ in the buffer composed of $50 \mathrm{mM}$ Tris $\mathrm{HCl}, \mathrm{pH} 7.5,10 \mathrm{mM} \mathrm{MgCl}_{2}$, $10 \mathrm{mM}$ DTT periodically $10 \mu 1$ aliquots were assayed for uncatalyzed EF-Tu.GDP exchange at $37^{\circ}(\mathrm{A})$ or EF-Ts catalyzed exchange at $0^{\circ}(\mathrm{B})$. Brackets in Figure $4 \mathrm{~B}$ indicate the standard error of two independent determinations

ceeded, the fraction of free EF-Tu decreased as the free GDP released by denaturation increased. Other experiments not shown here confirmed that both the wild-type and mutant $\mathrm{EF}-\mathrm{Tu}$ proteins are maximally active throughout the normal $25-45^{\circ} \mathrm{C}$ temperature range for the organism.

Figure 4B shows the loss of activity of EF-Tu as a substrate for EF-Ts in the EF-Ts-catalyzed exchange of EF-Tu. GTP with free GDP. The more rapid loss of activity in the HAK 88 strain indicates a decreased thermal stability in the mutant EF-Tu; however, this difference is too small to affect the growth of the organism at the normal growth temperature.

Characteristics of EF-TS from HAK88. Originally the HAK88 strain was characterized as having a temperature-sensitive mutation in EF-Ts (Kuwano et al., 1974); consequently we sought to duplicate the previous results to determine whether the mutation in EF-Tu was correlated in any way to this reported defect in EF-Ts. Contrary to the original report, we were unable to demonstrate any dysfunction in EFTs from our culture of HAK88. In particular, EF-Ts from the original HAK88 strain was reported to be inactivated at $50^{\circ} \mathrm{C}$ with a half-life of about three minutes. In contrast the EF-Ts from our culture of $\mathrm{HAK} 88$ has a half-life of about $20 \mathrm{~min}$ at $55^{\circ} \mathrm{C}$ (data not shown). This rate of inactivation closely resembles that of the EF-Ts from wild-type E. coli B. In an EF-Ts-dependent poly(U)-directed protein synthesis system, we were also unable to show any differential heat inactivation of the EF-Ts in post 
ribosomal supernatants from HAK88 relative to those from an $E$. coli B strain (data not shown).

Growth Characteristics of HAK88 Strains. Because the HAK88 strain from which we isolated the elongation factors differed from the original isolate in not showing temperature-sensitivity of EF-Ts, we sought to determine if another characteristic of the original strain, tRNA-dependence at elevated temperatures, was present in existing strains of $E$. coli HAK88. This comparison was accomplished using HAK88 strains kindly supplied by $M$. Kuwano (HAK88-MK), D. Schlessinger (HAK88-DS) and A. Travers (HAK88-AT) and following as carefully as possible the original protocol of Kuwano et al. (Kuwano et al., 1972). The results in Table 5 show that neither HAK88-AT, the strain used in this study, nor the other two could be shown to demonstrate a dependence for exogenous $E$. coli B tRNA at the elevated temperature. This result is the same as that obtained from the parent strain, HAK8, which is known to be permeable to tRNA (but is not temperature-sensitive) (Yamamoto et al., 1971). In each case where growth was reported, isolated colonies were seen in large numbers, ruling out growth due solely to cross-feeding. Differences among HAK88-MK, HAK88-DS and HAK88-AT were seen with respect to their temperature-sensitivity. HAK88AT appeared to be exquisitely sensitive to high temperatures while HAK88-DS was less so. HAK-88MK was intermediate in sensitivity. In order to fur-

Table 5. Growth of HAK88-MK, HAK88-DS and HAK8-AT on solid minimal medium in the presence and absence of $E$. coli $\mathrm{B}$ tRNA. Numbers in parentheses represent results from a repeat of the experiment

\begin{tabular}{lllll}
\hline Strain & Temperature & Condition & $\begin{array}{l}\text { Relative } \\
\text { Growth } \\
\text { after } 48 \mathrm{~h}\end{array}$ & $\begin{array}{l}\text { Relative } \\
\text { Growth } \\
\text { after } 96 \mathrm{~h}\end{array}$ \\
\hline HAK88-MK & $28^{\circ}$ & -tRNA & $4+$ & $4+$ \\
& & +tRNA & $4+$ & $4+$ \\
& $42^{\circ}$ & -tRNA & $1+$ & $1+(2+)$ \\
& & +tRNA & $2+$ & $2+(2+)$ \\
HAK88-DS & $28^{\circ}$ & -tRNA & $4+$ & $4+$ \\
& & +tRNA & $4+$ & $4+$ \\
& $42^{\circ}$ & -tRNA & $4+$ & $4+$ \\
HAK88-AT & $28^{\circ}$ & +tRNA & $4+$ & $4+$ \\
& & -tRNA & $4+$ & $4+$ \\
& $42^{\circ}$ & +tRNA & $4+$ & $4+$ \\
& & -tRNA & 0 & 0 \\
HAK8-AT & $28^{\circ}$ & +tRNA & 0 & 0 \\
& & -tRNA & $4+$ & $4+$ \\
& $42^{\circ}$ & +tRNA & $4+$ & $4+$ \\
& & -tRNA & $4+$ & $4+$ \\
& +tRNA & $4+$ & $4+$ \\
\hline
\end{tabular}

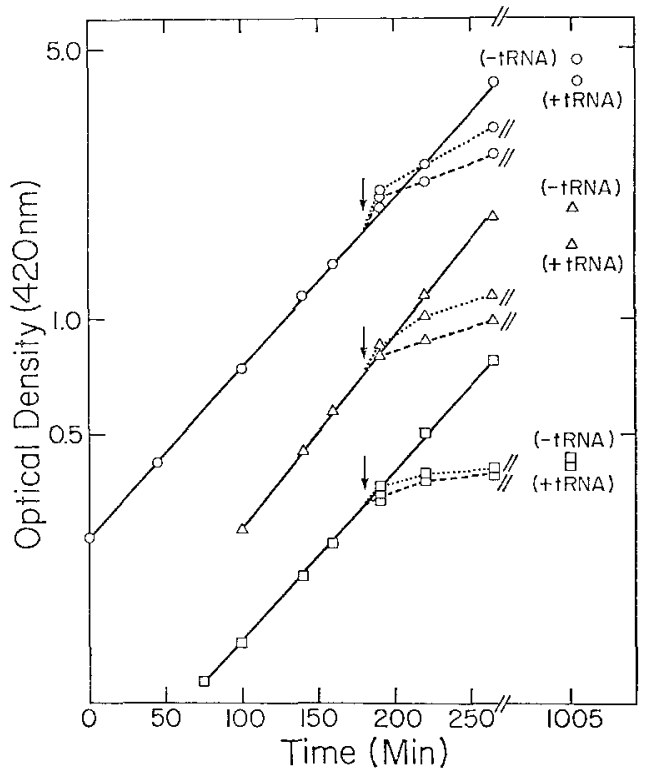

Fig. 5. Effect of temperature shift on the growth rates of HAK88MK, HAK88-DS and HAK88-AT. A flask containing $20 \mathrm{mls}$ of MOPS-rich medium was inoculated with a limited glucose culture and incubated at $30^{\circ} \mathrm{C}$. The solid lines represent the culture remaining at $30^{\circ} \mathrm{C}$. The vertical arrow indicates the time of the shift to $42^{\circ} \mathrm{C}$. The dotted line $(\cdots)$ ) after the shift represents a culture to which no additions were made. The dashed line (---) after the shift represents a culture to which $2 \mathrm{mg} / \mathrm{ml} \mathrm{E}$. coli B tRNA was added $8 \mathrm{~min}$ before the shift. In every case at $T=1005$ the upper point of the doublet represents the (-tRNA) condition while the lower point represents the (+tRNA) condition. The parallel slashed lines represent a discontinuity in the time scale. All cultures began with $6 \times 10^{6}$ cells $/ \mathrm{ml}$ and monitoring began at zero time (abscissa). (O- -0$)$ HAK88-MK, $(\triangle-\Delta-\triangle)$ HAK88-

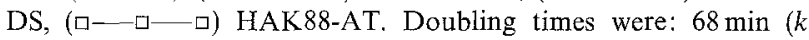
$=0.612)$, HAK88-MK; $60 \mathrm{~min}(k=0.693)$, HAK88-DS; $71 \mathrm{~min}(k$ $=0.586$ ), HAK 88 -AT

ther characterize the temperature-sensitivity data and to corroborate the data on tRNA-dependence, growth experiments in liquid medium, employing additions or not of tRNA prior to temperature shifts, were carried out. The results of this experiment are shown in Figure 5. These experiments, plus identical ones carried out in minimal medium (data not shown) showed that: (a) HAK88-MK, HAK88-DS and HAK88-AT grew in minimal and rich medium at the growth rates reported by Kuwano et al. (Kuwano et al., 1972) for the original isolate and (b) all three cultures showed a slowing or cessation of growth upon transfer to $42^{\circ} \mathrm{C}$ and (c) this effect was unaffected by the presence or absence of $E$. coli B tRNA (added prior to the shift).

\section{Discussion}

From the preceding results we conclude that, except for all small difference in its affinity for ribosomes, 
the mutant $t u f B$ gene product strongly resembles the wild-type $t u f A$ gene product in its interactions with components of the protein synthetic apparatus. The lower affinity of the mutant $t u f B$ protein for ribosomes is not caused by the mutation, since the normal $t u f B$ protein also binds to ribosomes only half as well as the tufA protein (D.L. Miller et al., accompanying paper).

Our inability to measure the rates of the reactions with the separate proteins prohibits us from accurately comparing the catalytic efficiencies of the proteins; however, it would be surprising if such an analysis altered the conclusion that the proteins function similarly. The results in Figure 3 show that the mixture of EF-Tu species from HAK88 exchange GDP as efficiently as E. coli B EF-Tu-GDP. Furthermore, knowing that the mutant protein does bind to ribosomes extensively, we conclude that the mutant protein must also hydrolyze GTP and be released from ribosomes. Otherwise, it would block peptide chain elongation and inhibit the growth of the bacteria; however, HAK88 was shown to grow at the same growth rate $(120 \mathrm{~min})$ in minimal medium at $30^{\circ} \mathrm{C}$ as the parent HAK8 strain (P. Lemaux, unpublished results) known not to contain the mutant tuf $B$ gene. As additional support for the contention that the mutant EF-Tu is non-inhibitory and reacts normally with ribosomes, we have demonstrated that the mixture of EF-Tu species from HAK88 promoted poly(U)-directed polyphenylalanine synthesis as efficiently as a similar quantity of EF-Tu from the HAK8 parent strain.

This report has described the similarities between the wild-type tuf $A$ gene product and the mutant tuf $B$ gene product. In a separate study (D.L. Miller et al., accompanying paper), it was found that the wildtype tuf $A$ and $t u f B$ gene products also do not differ substantially in any of the reactions in peptide chain elongation. Therefore, we conclude that the mutation in the $t u f B$ gene has not altered the protein significantly in its reactions in peptide chain elongation.

EF-Tu has been implicated in other cellular processes besides peptide chain elongation. It has been identified as a component of bacteriophage $\mathrm{Q} \beta$ replicase (Blumenthal et al., 1972), and it has been found to stimulate $E$. coli ribosomal RNA synthesis in vitro (Travers, 1973). In addition, the protein has been shown to be associated in some way with the cytoplasmic membrane (Jacobson and Rosenbusch, 1976) and to have certain actin-like properties (Beck et al., 1977). Recent results suggest that mutant and wild-type EF-Tu are found associated in equivalent amounts with the cytoplasmic membrane (Blumenthal, R., Jacobson, G., and Rosenbusch, J., manuscript in preparation). It is possible that the mutant protein differs from the wild-type protein in one of its other functions. Although the mutant protein may not function normally in any of these roles this inability is not reflected by altered growth of the mutant strains. They seem to grow normally (equivalent to the parent strain) at low temperatures in minimal and rich medium. We cannot rule out that altered synthesis of the mutant protein or something under its control influences the altered growth at elevated temperatures. In this regard it should be noted, however, that, although HAK88 from three sources contained approximately equal ratios of mutant to wild-type EF-Tu in steady state, they varied considerably in their sensitivity to temperature shifts to higher temperatures.

HAK88-AT which we examined in detail here differed from Kuwano's original strain in that it appeared to have an EF-Ts which was not temperature-sensitive under the conditions used here. Friesen et al. recently mapped the chromosomal location of EF-Ts and attempted to show that strain HAK 88 had a temperature-sensitive locus linked to dapD, a gene closely linked to EF-Ts (Friesen et al., 1976). They were unable to accomplish this. $\mathrm{Q} \beta$ replicase made from one of the currently existing HAK88 strains also does not show temperaturesensitivity as was reported for the original isolate (Hori et al., 1974) (T. Blumenthal, unpublished results). Additionally neither HAK88-MK, HAK88-DS nor HAK88-AT could be shown to require exogenous tRNA for growth at elevated temperatures even though care was taken to duplicate the conditions in the original experiments. HAK $88-\mathrm{MK}$, HAK88-DS and HAK88-AT were similar to the original isolate in being inhibited in growth to some degree upon shifting to $42^{\circ} \mathrm{C}$. This temperaturesensitivity was evidently unaltered by the presence or absence of exogenous tRNA. The temperaturesensitivity of these organisms does not seem to be due to the mutation in EF-Tu since (a) we were unable to demonstrate any temperature-sensitivity of the mutant EF-Tu in vitro and (b) transductants of $E$. coli JF376 containing the altered $t u f B$ gene show no growth temperature-sensitivity (Pedersen et al., 1976a). Two dimensional gels of the three cultures grown at elevated temperatures in the presence and absence of tRNA were compared visually and no differences in their protein patterns among the cultures or between the plus and minus tRNA conditions could be found (data not shown).

The original data showing that HAK 88 possessed a temperature-sensitive EF-Ts is strong. By adding wild-type EF-Ts the authors were able to restore the ability of heat-inactivated EF-Tu.EF-Ts to bind GDP and to form the ternary complex (Kuwano et al., 1974). These observations and others make remote the possibility that altered EF-Tu could explain 
their results. Therefore, we can only speculate as to the manner in which the present "copies" of HAK 88 derived from the original strain. Perhaps the $t u f B$ mutation now present in the strain may have arisen as a compensatory mutation to the original EF-Ts ${ }^{\text {ts }}$ mutation and at some later time the EF-Ts gene reverted to temperature-resistance.

For the purpose of investigating the control of gene expression in E. coli, the EF-Tu mutation will serve as a valuable probe for monitoring the differential translation of the tufA and $\operatorname{tuf} B$ genes. From the similarity of the properties of the two EF-Tu gene products we suspect that they would be subject to the same regulatory processes. In a recent study by Reeh et al., (Reeh, et al., 1976) the authors chose to make use of the tufB mutation in order to study the regulatory pattern of the two proteins. In general, it appeared that both gene products are regulated identically in relaxed cells with some differences in stringent cells. This difference could be a true reflection of differences between normal tuf $A$ and tufB or it could be due to the tufB mutation. It is interesting to note the effect of a temperature shift alone on the rate of synthesis of these proteins. While the relative rate of synthesis of the normal tuf $A$ gene is unaffected by a shift from $30^{\circ} \mathrm{C}$ to $40.5^{\circ} \mathrm{C}$, tuf $B$ synthesis is elevated almost two-fold. Although this too may be a reflection of the mutation, there is some indication that normal EF-Tu (composed of the tuf $A$ and $t u f B$ gene products) is elevated in a comparable temperature shift to the extent predicted by these results and promoter efficiencies of tuf $A$ and tufB (Lemaux, P.G., S.L. Herendeen, P.L. Bloch and F.C. Neidhardt, manuscript in preparation). In addition to its use in studying the regulation of the two genes, the mutant EF-Tu should also serve as an excellent marker for examining the function of the two normal gene products in other reactions of EF-Tu.

Acknowledgement. This work was done in partial fulfillment of the requirements for the $\mathrm{Ph}$. D. degree by PGL, who was supported by a Fredrick G. Novy Research Fellowship.

\section{References}

Beck, B.D., Arscott, P.G., Jacobson, A.: Structural and functional similarities of elongation factor EF-Tu and actin. Proc. nat. Acad. Sci. (Wash.) (1977) (in press)

Blumenthal, T., Landers, T.A., Weber, K.: Bacteriophage $\mathrm{Q} \beta$ replicase contains the protein biosynthesis elongation factors EFTu and EF-Ts. Proc. Nat. Acad. Sci. (Wash.) 69, 1313-1317 (1972)

Friesen, J.D., Parker, J., Watson, R.J., Benoiak, D., Reeh, S.V., Pedersen, S.: A transducing bacteriophage $\lambda$ carrying the structural gene for elongation factor Ts. Molec. gen. Genet. 148, 93 98 (1976)
Glazier, K., Schlessinger, D.: Magic spot metabolism in an Escherichia coli mutant temperature sensitive in elongation factor Ts. J. Bact. 117, 1195-1200 (1974)

Gordon, J.: Regulation of in vivo synthesis of the polypeptide chain elongation factors in Escherichia coli. Biochem. 9, 912917 (1970)

Gordon, J., Lucas-Lenard, J., Lipmann, F.: Isolation of bacterial chain elongation factors. In: Methods in Enzymology 20, Part C, 281-302 (1971)

Hachmann, J.P., Miller, D.L., Weissbach, H.: Purification of factor Ts. Studies on the formation and stability of nucleotide complexes containing transfer factor Tu. Arch. Biochem. Biophys. 147, 457-466 (1971)

Hori, K., Harada, K., Kuwano, M.: Function of bacteriophage Q $\beta$ replicase containing altered subunit IV. J. molec. Biol. 86, 699708 (1974)

Jacobson, G.F., Rosenbusch, J.P.: Abundance and membrane association of elongation factor Tu in E. coli. Nature (Lond.) 261, 23-26 (1976)

Jaskunas, S.R., Lindahl, L., Nomura, M., Burgess, R.P.: Identification of two copies of the gene for the elongation factor EFTu in E. coli. Nature (Lond.) 257, 458-462 (1976)

Kuwano, M., Endo, H., Kamiya, T., Hori, K.: A mutant of Escherichia coli blocked in peptide elongation: Altered elongation factor Ts. J. molec. Biol. 86, 689-698 (1974)

Kuwano, M., Endo, H., Yamamoto, M.: Temperature-sensitive mutation in regulation of ribonucleic acid synthesis in Escherichia coli. J. Bact. 112, 1150-1156 (1972)

Lucas-Lenard, J., Lipmann, F.: Protein biosynthesis. Ann. Rev. Biochem. 40, 409-448 (1971)

Miller, D.L., Weissbach, H.: An interaction between the transfer factors required for protein synthesis. Arch. Biochem. Biophys. 132, 146-150 (1969)

Miller, D.L., Weissbach, H.: Elongation factor $\mathrm{Tu}$ and the aminoacyl-tRNA.EF-Tu.GTP complex. In: Methods in Enzymology 30, Part F, 219-231 (1974)

Neidhardt, F.C., Bloch, P.L., Pedersen, S., Reeh, S.: Chemical measurement of steady-state levels of ten aminoacyl-transfer ribonucleic acid synthesis in Escherichia coli. J. Bact. 129, 378387 (1977)

Neidhardt, F.C., Bloch, P.L., Smith, D.F.: Culture medium for enterobacteria. J. Bact. 119, 736-747 (1974)

O'Farrell, P.: High resolution two-dimensional electrophoresis of proteins. J. biol. Chem. 250, 4007-4021 (1975)

Pedersen, S., Blumenthal, R., Reeh, S., Paricer, J., Lemaux, P., Laursen, R.A., Nagarkatt, S., Friesen, J.D.: A mutant of Escherichia coli with an altered elongation factor Tu. Proc. nat. Acad. Sci. (Wash.) 73, 1698-1701 (1976a)

Pedersen, S., Reeh, S.V., Parker, J. Watson, R.J., Friesen, J.D., Fiil, N.P.: Analysis of proteins synthesized in ultraviolet lightirradiated Escherichia coli following infection with bacteriophages $\lambda d r i f^{d} 18$ and $\lambda d f u s-3$. Molec. gen. Genet. 144, 339343 (1976b)

Reeh, S., Pedersen, S., Friesen, J.D.: Biosynthetic regulation of individual proteins in relA ${ }^{+}$and relA strains of Escherichia coli during amino acid starvation. Molec. gen. Genet. 149, 279-289 (1976)

Travers, A.: Control of ribosomal RNA synthesis in vitro. Nature (Lond.) 244, 15-18 (1973)

Yamamoto, M., Ishizawa, M., Endo, H.: Ribonucleic acidpermeable mutant of Escherichia coli. J. molec. Biol. 58, 103115 (1971)

Communicated by H.G. Wittmann

Received July 28/September 20, 1977 